\title{
¿Cómo superar las pobrezas generadas por la conservación? Desarrollo endógeno en las comunidades mapuche aledañas al Parque Nacional Villarrica, Chile
}

\author{
Maritza Marín-Herrera \\ Universidad de Costa Rica, San José, Costa Rica. \\ Email: maritza.marin@ucr.ac.cr
}

\begin{abstract}
Resumen: En esta investigación, seexploran las alternativas a las formas de gestionar el territorio, que construyen las comunidades mapuche aledañas al sur del Parque Nacional Villarrica (PNV). Igual que otras unidades de conservación, el establecimiento del PNV implicó invisibilizar las prácticas ancestrales y alejarles de las riquezas materiales y simbólicas presentes en el territorio. Ante las políticas propias del modelo de desarrollo dominante que coloca su interés en el potencial turístico, en los bienes y en los servicios ecosistémicos presentes en la zona, se torna relevante el contenido que las comunidades le dan a este espacio desde sus propias capacidades, buscando un tipo de desarrollo alternativo que facilite experimentar la autodeterminación y enfrentar el empobrecimiento. Se concluye que la reapropiación territorial del PNV es fundamental para superar las pobrezas inmateriales y que las comunidades cuentan con herramientas propias para gestionar de manera autónoma y sinérgica el territorio.
\end{abstract}

Palabras Claves: Territorio mapuche, Parque Nacional Villarrica, desarrollo endógeno, pobrezas

\section{How can we overcome the poverty generated by conservation? Endogenous development in the Mapuche communities surrounding the Villarrica National Park, Chile}

\footnotetext{
Abstract: This research explores alternatives to the forms of land management built by Mapuche communities south of Villarrica National Park (PNV). Like other conservation units, the establishment of the PNV implied making ancestral practices invisible and distancing them from the material and symbolic wealth present in the territory. Before the policies of the dominant development model that places its interest in the tourist potential, in the goods and in the ecosystem services present in the zone, the content that the communities give to this area from their own capacities becomes relevant, looking for an alternative type of development that
} 
facilitates experiencing self-determination and facing impoverishment. We conclude that the territorial re-appropriation of the PNV is fundamental to overcome immaterial poverty and that the communities have their own tools to manage the territory autonomously and synergetically.

Keywords: Mapuche territory, Villarrica National Park, endogenous development, poverty

\section{Como superar as pobrezas gerada pela conservação? Desenvolvimento endógeno nas comunidades Mapuche em torno do Parque Nacional Villarrica, Chile}

Resumo: Nesta pesquisa, são exploradas as alternativas às formas de gestão do território, que são construídas pelas comunidades mapuches localizadas ao sul do Parque Nacional Villarrica (PNV). Como outras unidades de conservação, o estabelecimento do PNV implicou a invisibilização das práticas ancestrais e o distanciamento das riquezas materiais e simbólicas presentes no território. Perante as políticas próprias do modelo de desenvolvimento dominante que centra seu interesse no potencial turístico, nos bens e serviços ecossistêmicos presentes na área, torna-se relevante o conteúdo que as comunidades dão a este espaço a partir de suas próprias capacidades, procurando um tipo de desenvolvimento alternativo que facilita a experimentação da autodeterminação e o enfrentamento do empobrecimento. Conclui-se que a reapropriação territorial do PNV é fundamental para superar as pobrezas imateriais e que as comunidades disponham de ferramentas próprias para administrar de forma autônoma e sinergética o território.

Palavras-chave: Território mapuche, Parque Nacional Villarrica, desenvolvimento endógeno, pobrezas

$* * *$

\section{Introducción}

Conservar los recursos naturales a través de la constitución de unidades naturales de conservación por parte de los estados, ha generado históricamente el desplazamiento de las comunidades originarias (Martinez-Alier, 2014), cuya actualización de las necesidades humana fundamentales $(\mathrm{NH})$ está directamente relacionada con sus territorios. Tales declaratorias invisibilizanlos usos y prácticas ancestrales, a la vez provocan el alejamiento a la riqueza y acceso a los "bienes y servicios” proporcionados por la naturaleza,generando pobrezas en las dimensiones material y simbólica.

Los estados cuyo modelo de desarrollo dominante pone énfasis en el crecimiento económico, seinteresanen las unidades naturales de conservación, como potenciales zonas de desarrollo por su atractivo turístico, por contener fuentes de materias primas y servicios ecosistémicos. A su vez, como producto de las luchas de los movimientos indigenistas, los más recientes paradigmas de conservación reconocen y 
promueven el aporte de las comunidades indígenas para preservar estas unidades (FAO, 2008).

A partir de la década de los años 80las comunidades comienzan a demandar el uso de los recursos naturales demanera sostenible, exigencia que coincide con el debilitamiento de los estados como producto de los programas de ajuste estructural y su imposibilidad de administrar las zonas de protección por falta de recursos.Así, se encuentran casos como la población Miskita en Nicaragua,comunidades locales en Cahuita, Costa Rica y comunidades Mapuche en Argentina, que desarrollan experiencias de participación conjunta estado-comunidad para la administración de unidades de conservación. En el caso delas comunidad Mapuche, tanto la Neuquinaen el Parque Nacional Lanín, como la Maliqueo en el Parque Nacional Nahuel Huapi participan de experiencias de co-gestión o co-manejo.

Al indagar este tipo de acuerdos en América Latina a partir de la década de los ochenta (McCarthy \& Martínez, 2006; Carpinetti, 2007; Trentini y Tyelman, 2009; Trentini, 2011; 2012),se localizan aciertos y errores en los procesos de negociación entre los estados y las comunidades. Si bien es cierto, no dan soluciones definitivas para el reconocimiento de los derechos de lospueblos originarios sobre sus territorios ancestrales, han sido una ventana para gestionar los conflictos acumulados por décadas, conflictos que aumentan en el instante en que la naturaleza se percibe como un recurso mercantil e ideológico, en un objeto de disputa entre diferentes agentes estatales, entes privados y los habitantes ancestrales.

En este trabajo se exploran las alternativas que se vienen construyendo en las comunidades mapucheextendidas al sur delPNV,para ser partícipes de la administración y gestión del parque, como opción para recuperar un territorio del que se les despojó desde 1912, año en que inicialmente se establece ese espacio como reserva forestal. Dicha declaratoria corresponde a una ontología de la modernidad,pues impone la separación entre el ser humano y la naturaleza como única opción para conservar la última.

Se discute la relación entre las condiciones de pobreza y vulnerabilidad experimentadas por las poblaciones participantes del estudio a partir del planteamiento de la "Teoría del Desarrollo a Escala Humana” (DEH), expuesta en el primer apartado.La estrategia metodológica, detallada en un segundo momento, tiene como eje el método etnográfico con el cual se posibilita dar vos a quienes experimentan cotidianamente las pobrezas estudiadas. Posteriormente, se contextualiza el espacio estudiadoa fin de realizar el análisisde las pobrezas generadas a partir de la constitución del PNV, así como las potencialidades comunales para la construcción dialógica de alternativas. 


\section{¿Cómo superar las pobrezas generadas por la conservación?}

\section{Referentes teóricos}

En este artículo, seexplora desde la perspectiva teórica DEH, una concepción de pobreza que se distancia de lapredominante en las últimas décadas, específicamente la línea de pobreza, que hace relación con el indicador para medirla de acuerdo con la posibilidad de cubrir o no las necesidades básicas. Según dicho método, las necesidades básicas son preestablecidas por un conjunto de bienes materiales necesarios para la subsistencia de las personas, asignando un monto per cápita para adquirirlas.

$\mathrm{Al}$ contrario de ese planteamiento, el DEHplantea la pobreza como una problemática que trasciende el ámbito material, y le da un carácter multidimensional. A partir de la definición de nueve necesidades básicas fundamentales, axiológicas e inmateriales: creación, identidad, subsistencia, protección, ocio, afecto, participación, libertad y entendimiento; y cuatro necesidades existenciales: ser, tener, hacer y estar, se identifican múltiples pobrezas producidas por no lograr ser vividas o actualizadas positivamente (Max-Neef,Elizalde y Hopenhayn, 1998).En su planteamiento el DEH, trasciende la centralidad del crecimiento económico, y plantea la necesidad de una economía al servicio de las personas y no a la inversa, como sucede en el modelo de desarrollo dominante.

El DEHentiende por bienes, la materialidad de las necesidades. Entre las necesidades y los bienes se encuentran los satisfactores entendidos como "formas mediante las cuales en cada cultura, en cada sociedad, en cada circunstancia histórica se buscan y diseñan las mejores formas de actualizar las necesidades de sus integrantes” (Elizalde, 2003). Para identificar los bienes y los satisfactores, en este artículo,se enfatizala dimensión “estar” y su interrelación con las necesidades axiológicas.

Otro eje de esta teoría es la autodependencia, esta implica la interdependencia horizontal que evita el autoritarismo y la unidireccionalidad de las decisiones. Además, posibilita la sinergia de necesidades como la identidad, la creatividad, la participación y libertad, en tanto potencia su demanda. El DEH considera el espacio local como el lugar para generar "embriones de autodependencia cuyas prácticas constituyan alternativas potenciales a las grandes estructuras piramidales de poder” (Max-Neef, Elizalde y Hopenhayn, 1998,p. 91).

Desde la aprobación del Convenio 169 de la OIT en el año 1989, los conceptos de autonomía y autodeterminación tomaron relevancia en toda discusión relacionada con la vida de los pueblos indígenas. Para efectos de este artículo, se consideran ambos conceptos como parte de la propuesta de autodependencia ${ }^{1}$, pues el contenido conceptual es cercano, en tanto se 
busca la construcción endógena y generación desde abajo de las formas de gobernar y gestionar los territorios locales.

Los procesos de reapropiación territorial, donde las comunidades definan sus proyectos de manera endógena, toman relevancia y se convierten en luchas por la apropiación de la naturaleza,como sucede con las comunidades estudiadas. Estas luchas se manifiestan a nivel político-jurisdiccional, así como en el reconocimiento de autonomías.

De esta manera, las poblaciones indígenas están generando nuevos derechos culturales para recuperar el control sobre su territorio como un espacio ecológico, productivo y cultural para reapropiarse un patrimonio de recursos naturales y significados culturales (Leff, 2000,p. 65)

Ante las situaciones de despojo experimentado por las comunidades originarias en los parques nacionales, la recuperación de los espacios es fundamental para reconstruir sus modos de vida. Es decir, es en un campo epistémico-político, donde los pueblos indígenas y otros grupos "reinventan” sus territorios como el lugar-espacio-tiempo de reapropiación cultural de la naturaleza (Leff, 2014).

En esta discusión confluyen la sustentabilidad ambiental, el derecho a la autonomía o autogobierno y la autodeterminación ${ }^{2}$ de los pueblos originarios. De ahí la importancia de recuperar el territorio, como un modo de recuperar los modos de vida y la relación con la naturaleza de las comunidades mapuche, así como autodefinir sus proyectos comunitarios en el ámbito económico, social y cultural.

Por otra parte, la articulación orgánica como tercer pilar del DEH, considera la necesidad de complementariedad entre diferentes espacios: local-nacional-global, de tal manera que se estimula el potenciamiento recíproco entre procesos de identidad sociocultural, de autonomía política y de autodependencia económica. En este sentido, el DEH plantea como desafío central "conciliar la promoción desde fuera con las iniciativas desde adentro”(Max-Neef, Elizalde y Hopenhayn, 1998, p. 89).

Para comprender el ejercicio autonómico que los pueblos originarios intentan realizar, en contextos de "articulación forzada” entre lo local-nacionalglobal, se recurre al concepto “autonomía relacional” acuñado por Astrid Ulloa.

La autonomía relacional indígena debe ser entendida como la capacidad de los pueblos indígenas para ejercer autodeterminación y gobernabilidad en sus territorios a partir de las relaciones, negociaciones, confrontación y participación que tienen que establecer con el Estado y diversos actores locales, nacionales y transnacionales en la búsqueda de reconocimiento e implementación de su autonomía política y territorial, cuando retomen políticas o procesos estatales o transnacionales para su consolidación. (Ulloa, 2011,p. 481). 
Precisamente, ante las presiones que enfrentan los territorios indígenas por el uso de los recursos, desde el ámbito nacional e internacional, los pueblos originarios desarrollan herramientas para r-existir. Despliegan mecanismos para reivindicar sus derechos, hacen uso de la legislación transnacional y, sobre todo, establecen negociaciones y participan con el estado en la construcción de políticas y proyectos que les afectan.

\section{Metodología}

La pobreza analizada desde el DEHrevierte una gran complejidad, pues requiere conocer las particularidades de los grupos humanos que la enfrentan. De ahí que se recurre a un enfoque etnográfico, para identificar y analizar el fenómeno de la pobreza desde la narrativa de sus actores y su marco de referencia acerca de los procesos y conflictos que enfrentan.

Asimismo, las alternativas para superar las pobrezas expuestas al final del trabajo, se recogen desde las voces de las personas participantes de la investigación y se sistematizan a partir del concepto de desarrollo endógeno, donde la autodependencia y la articulación orgánica son los ejes que posibilitan un tipo de desarrollo alternativo y sinérgico.

Este trabajo aborda cualitativamente la problemática de las comunidades tradicionales colindantes con el PNV: Carlos Antimilla, Juan Caripán, Juan Chañapi y Ramón Chincolef. Las cuatro presentan conflictos con el Estado chileno por el uso y propiedad del territorio considerado parte del PNV, espacio en el que se localizan satisfactores y bienes históricamente vinculados a la actualización de sus necesidades humanas. Estas comunidades se diferencian entre sí por sus formas organizativas y de relación con el territorio, por lo cual su tratamiento metodológico fue diferenciado.

El universo de estudio lo constituye la población Mapuche que habita las comunidades seleccionadas. Se combinan como criterios muestrales la accesibilidad con la selección estratégica de casos. La investigación contó con la participación de 5 organizaciones comunales mediante el contacto con sus líderes y con 28 personas (16 hombres y 12 mujeres) con quienes se realizaron grupos focales, entrevistas,recorridos en terreno y un taller. Algunas de las personas participantes prefirieron mantener el anonimato, por lo que se utilizan siglas o pseudónimos al citar sus aportes, según corresponda.

\section{Contexto sociodemográfico y políticas de desarrollo turístico}

La comunidades estudiadasRamón Chincolef, Juan Chañapi, Traitraico, Juan Caripán y Carlos Antimilla, fueron establecidas mediante Títulos de Merced, otorgados en los años 1912-1913 por el Estado Chileno 
(Aylwin, 2008); se ubican en la comuna de Panguipulli, Región de Los Ríos,pertenecen al distrito censal Coñaripe ybordean el Parque Nacional Villarrica.

El distrito Censal Coñaripe representa un 12,5\% del total del territorio de la comuna de Panguipulli, con una extensión de 410,5 km²(Instituto Nacional de Estadística, 2008), siendo su población 3946 habitantes, según el Censo $2002^{3}$. De su población total, el 50,5\% es mapuche (Municipalidad de Panguipulli, 2014, pp. 160-161).

Según la actualización del Plan de Desarrollo Comunal (PLADECO), Coñaripe posee una importante "dispersión de localidades pobladas y asentamientos rurales, debido a lo extenso de su Territorio”, lo que dificulta el acceso a los servicios disponibles en el municipio y a la asistencia social del 93,78\% de la población considerada vulnerableque habita la zona (Municipalidad de Panguipulli, 2014).

En cuanto al desempleo, se señala una incidencia del 12,1\%. Las principales actividades económicas la agricultura, la ganadería, la caza, la silvicultura, la extracción de madera, la apicultura y la artesanía. Además, existen pequeños productores de frutales, de cultivos en invernaderos y ganado de engorde. El turismo ha pasado a formar parte de las actividades económicas relevantes, ligadas a la oferta de aguas termales durante todo el año, lo cual constituye una fuente de empleo importante. Además en la época estival la atracción por los lagos y ríos de la zona aumenta la demanda de servicios turísticos.

Según el PLADECO, Coñaripe, Traitraico, entre otros lugares, destacan por las posibilidades de realizar etnoturismo, pues son comunidades mapuche que "mantienen sus rasgos culturales y sus tradicionales modos de vida” (Municipalidad de Panguipulli, 2014, p. 50).Además del potencial turístico, todas estas comunidades por ser aledañas al PNV son propuestas como parte de la zona de amortiguamiento, lo cual coloca parte de su territorio como áreade protección asociada a dicha unidad de conservación.

Por otra parte, instituciones como la Corporación Nacional Forestal (CONAF), la Corporación de Fomento de la Producción (CORFO), Bienes Nacionales, el Servicio Nacional de Turismo (SERNATUR) y la Municipalidad de Panguipulli, así como privados y organizaciones no gubernamentales, reconocen su importancia como zona de influencia socio-económica por permitir "la recuperación, el manejo y la utilización sustentable de recursos naturales (...) dado el impacto positivo que pueden poseer actividades demostrativas al interior de ellas, y por la amortiguación de impactos que puede significar las actividades del entorno" (Corporación Nacional Forestal, 2013, p. 19).

De ahí se deriva una fuerte presión territorial en busca de un desarrollo económico basado en el uso de los bienes y servicios que proporcio- 
nan los ecosistemas del Parque (Corporación Nacional Forestal, 2016, 2013; Gobierno de Chile, 2012, 2013; Municipalidad de Panguipulli, 2006). Por ejemplo, el Plan de Manejo del Parque Nacional Villarrica propone generar condiciones que fomenten la visitación de turistas al lugar;mientras que para los “colonos” plantea la necesidad de hacer un control de sus prácticas y relacionamiento con el parque. La CONAF reconoce la riqueza presente en el lugar, pero plantea incorporarlo a las actividades que dinamizan el sistema económico dominante, mediante el desarrollo de la actividad turística.

Por su parte, la Estrategia Nacional de Turismo 2012-2020 busca incorporar plenamente la zona a la dinámica del capital, mediante el posicionamiento del PNV como destino y producto nuevo dentro de la industria turística nacional (Gobierno de Chile, 2012).

En el Plan Maestro del año 2013, el PNV se prioriza como un área protegida con potencial turístico, por lo cual se incluye en la política gubernamental, para su "desarrollo sustentable”, lo que trae aparejado la construcción de nueva infraestructura para posibilitar el acceso y atracción de mayor cantidad de turistas, con implicaciones en los modos de vida de las comunidades mencionadas.

Una de las obras propuestas de mayor impacto, para construir a corto plazo, es un camino pavimentado que conecta las localidades de Palguín y Coñaripe, cruzando por Los Cajones, según reza en el Plan Maestro "La proyección de un camino asfaltado interregional que conectará las localidades de Palguín y Coñaripe convertirá a Quetrupillán en un área estratégica para el desarrollo turístico del Parque” (Gobierno de Chile, 2013, p. 24).

Esto significa, no sólo la conexión de dos localidades, sino también el "encuentro" de dos estilos de desarrollo diferentes, donde prevalece un tipo de turismo convencional en la comuna de Pucón y el intento por generar condiciones para un turismo de base comunitaria, mediante proyectos que las mismas instituciones gubernamentales han venido financiando en la comuna de Panguipulli, específicamente Pocura, Los Cajones y Traitraico, que nos ocupan ${ }^{4}$.

Estas obras tienen implicaciones en el entorno natural y afectan la relación de la población mapuche con uno de sus elementos sagrados, la araucaria, pues propone "botar” algunos de estos árboles para posibilitar la ampliación de la calle que cruza el parque. Este hecho tiene en alerta a las organizaciones de la zona que tienen que definir según el Convenio 169, su consentimiento previo, libre e informado.

Este interés económico y recreativo se complementa con otra forma de relacionarse con el parque, ahora para fines educativos y científicos. Se recurre a su zonificación como herramienta para la ordenación del espacio, según criterios que sirven como "base para definir el nivel y tipo de inter- 
venciones que garantizarán el cumplimiento de los objetivos de preservación y conservación de las áreas protegidas” (Corporación Nacional Forestal, 2013, p. 117).

En síntesis, la población de las comunidades participantes en este estudio, según los parámetros estatales, se encuentran en condición de vulnerabilidad social y enfrentan una alta tasa de desempleo. Sin embargo, se ubican en un entorno cuyos atractivos naturales las colocan como zonas de interés turístico.

La denominada vocación turística de la zona es un potencial para el mejoramiento de la calidad de vida de las comunidades, a la vez que se conforma como una nueva fuente de empobrecimiento de las comunidades ancestrales, mediante la colonialidaddel saber y el poder, evidenciadas en las políticas institucionales señaladas párrafos atrás.

\section{Neocolonialidad y unidades de conservación}

Si bien el primer objetivo que inspira la creación de reservas naturales y parques nacionales alrededor del mundo es el preservacionismo, en América Latina y el resto de colonias europeas, este responde también a la problemática de la colonización y la explotación indiscriminada de los recursos naturales. Ejemplo de ello es elParque Nacional Yellowstone, cuya creación en 1872, busca proteger la naturaleza de la intervención del ser humano y limitar la expansión de la colonización en espacios de gran belleza escénica, sin tomar en cuenta la presencia previa de grupos humanos que conviven ancestralmente con ella. En este sentido, muchos de los parques nacionales "se establecieron después del desplazamiento o eliminación de los pueblos nativos que vivían en estos territorios” (Martínez-Alier, 2014, p. 30).

La viabilidad del proyecto moderno requiere una transformación en la forma de relación entre el ser humano- naturaleza, lo cual implica la imposición de una nueva ontología que les separa.Así el hombre, blanco y europeo, encarna una civilización que impone un orden de reparto del mundo, acuerpado por la Iglesia. Se instituye la misión de apropiarse de los recursos naturales y sojuzgar todas las formas de vida salvaje y, paradójicamente, también se incentiva el gozo estético por la naturaleza virgen y el interés de crear espacios protegidos de la acción humana.

De esta forma, la naturaleza debe ser conservada y, para ello, no puede ser habitada ni usada por seres humanos, sino es para efectos de contemplación y de turismo, generándose "la idea de un territorio vacío y de una naturaleza intacta (lo cual) pertenece a la lógica colonial, ya que excluye a quienes han habitado e intervenido un territorio a lo largo de la historia.” (Duran, 2009, p. 62).

La conservación de la naturaleza se concibe, entonces, como un modo de mitigar los daños causados por la expansión del capital bajo la 
dinámica del "sistema mundo capitalista”, sustentado en el "ejercicio de la violencia y el despojo, en la usurpación material y simbólica, no sólo de los recursos naturales, sino del sentido, del saber y del ser" (Guerrero, 2010, p. 24).

Se establecen así, espacios naturales sin personas, se desplaza a las comunidades que dependen de ellos para la subsistencia, hacia fuera de sus fronteras. Se conciben espacios sacralizados y, a la vez, escindidos de la acción humana.

En noviembre de 1940, mediante decreto supremo No. 2236 se crea el PNV, ubicado en la Región de la Araucanía y la Región de Los Ríos en Chile. Los terrenos que lo contienen se consideraban inútiles para la agricultura, la ganadería y para el uso forestal, "por ello no fueron asignados a colonos" (Corporación Nacional Forestal, 2006, p. 8).

Con esa declaratoria se funda una nueva forma de colonialidad, que si bien posibilita la conservación de flora y fauna nativa; también separa al pueblo Mapuche de su territorio y las prácticas culturales asociadas a él. Por tanto, se impone la dicotomía ser humano-naturaleza propia de la modernidad y su matriz colonial de poder"colonizando y sub-alternizando otras formas de ser, de sentir, de pensar, de hacer, de tejer la vida” (Guerrero, 2010, p.12).

\section{Pobrezas generadas por la conservación}

El pueblo Mapuche en Chile guarda en su memoria un historial de despojo(Millalén,2006; Correa y Mella, 2010), donde la creación del PNV es uno más de los experimentados por las comunidades mapuche del sur de Chile. El destino dado a las 63.000 hectáreas que lo conforman, es una de las razones por las cuales los reclamos territoriales son invisibilizados, ya que la conservación es un tema de relativo consenso entre el saber/poder científico-político y los intereses de resguardo de las comunidades mapuche, aunque esto implica evadir la conflictividad presente en el lugar y la consecuente generación de pobrezas y disputa de territorialidades.

Para abordar las pobrezas desde una visión territorial, la dimensión "estar" delas necesidades humanas fundamentales permite identificar dos espacios de interacción diferenciados presentes en el discurso de las personas participantes en la investigación: el Rucapilláno "Volcán Villarrica" y sus faldeos, entendidos como satisfactores de las $\mathrm{NH}$.

Estos dos satisfactores, en la cosmovisión de las comunidades mapuche,son un continuo que conforma su territorio. La existencia mapuche es posible y encuentra sentido en un territorio que va desde la boca del volcán hasta el lago Calafquén, concepción reflejada en lo expresado por la dirigente del Parlamento de Coz Coz, quien plantea que el concepto de parque como zona de conservación no encuentra sentido en la visión del 
mapuche, sino que es un espacio que forma parte de un territorio ancestral, "un espacio común, tu espacio habitual” (BC, comunicación personal, 23-4-2015).

De la relación que establecen las comunidades mapuche con el Rucapillán, se desprende una fuerte interdependencia de su cosmovisión con el territorio. Este "hermano", en su relación afectiva, les protege y contribuye a su subsistencia cultural y biológica, es un elemento de cohesión comunitaria e identitaria, de participación, creación, ocio y entendimiento.

Como satisfactor de la subsistencia, se señala al volcán que permanece nevado todo el año, como el proveedor del agua que permite la vida de los habitantes del lugar, tanto humanos como no humanos. El agua ofrecida por el pillán, producto de los deshielos, es agua pura para el consumo humano, de la cual se sienten orgullosos los vecinos, pues es el resultado del cuidado y su buena relación con el territorio; asimismo, mantiene el verdor en las zonas donde se realizó ancestralmente el pastoreo ${ }^{5}$.

Otro "bien” que actualiza la necesidad de subsistencia, y lo aporta el Rucapillán, es el newen o energía, parte fundamental de la espiritualidad mapuche. Una líder de la comunidad Carlos Antimilla plantea la existencia de un flujo energético que hay entre el volcán y las zonas bajas, entre ambos espacios suben las rogativas, los pagos y baja el newen.

En los actos de pedir y agradecer, se establecen ceremonias como el guillatún donde se congrega la comunidad para guillatukar ${ }^{6}$ u orar a Gnechén ${ }^{7}$, según cuenta la esposa del lonko de una de las comunidades. La rogativa inicia en el pillán y viene bajando por los diferentes cerros, pasando por el lawen $^{8}$ hasta llegar al lago (notas de campo, 1-5-2015).

Estas rogativas establecían relaciones sinérgicas entre la identidad y la participación, que se ven afectadas por el ingreso de otras religiones y otros bienes que incentivan la deserción a esas ceremonias, pues instalan otras cosmoexistencias. También aparecen varios bienes sustitutivos, la religión que pasa del guillatún al cristianismo, es decir,Gnechén deja de ser su Dios; las rogativas pasan a ser una actividad donde el dinero toma un papel relevante, pues los consumos se han trasladado al mercado, y la reducción territorial ha generado empobrecimiento material y modos de vida cada vezmás dependientes del mercado externo.

Como parte de la necesidad de ocio, algunos miembros de la comunidad realizan con sus familias actividades que conforman espacios para la comunicación y el disfrute con el volcán. Algunos bienes asociados son el aire puro y el agua.

Por otra parte, los faldeos del Rucapillán conforman un satisfactor sinérgico definido en el estar, es decir, es el punto de encuentro entre lo material e inmaterial, que facilita la interacción entre las nueve necesidades 
humanas y los múltiples bienes presentes en él. Es el lugar referente para muchas actividades comunitarias. Aquí confluyen dos prácticas, el piñoneo y la veranada. La primera se refiere a recolección del piñón ${ }^{9}$ o piñonada, práctica cultural de gran relevancia para las comunidades aledañas al parque, se acompaña de una rogativa a Gnechén para que la producción de piñón sea abundante. La segunda, la veranada, consiste en el alojamiento temporal en las faldas del volcán, donde se dan arbustos y frutos silvestres de alto valor nutritivo, aprovechados para la recolección y el engorde del ganado; permite la rotación de los terrenos bajos desgastados en el invierno y que experimentan sequedad en la primavera y verano.

Entre los bienes asociados a este satisfactor están los sayel ${ }^{10} O$ rukas, lugar de refugio y convivencia mientras se realizan las piñonadas, son una estructura material que hacía posible la actualización de las necesidades de protección, identidad, subsistencia, entendimiento, afecto, ocio.

En la década de los 70, laCONAF derribó los sayal,con lo cual se profundizó el proceso de despojo territorial y con ello la generación de pobrezas, pues si bien las piñonadas y el pastoreo de animales se siguen realizando, al no contar con ese espacio material de refugio, la práctica se va adaptando a las nuevas condiciones:

- La cantidad de días dedicados a la actividad disminuye, pues no cuentan con un lugar para protegerse del frío, para dar refugio a la familia, en especial a los niños que formaban parte de la práctica.

- La participación de los miembros de la familia se ve reducida, ya no se cuenta con condiciones materiales para resolver por varios días su sustento. En el sayel se guardaban los utensilios con los cuales se procesaba el piñón, los diferentes hongos y frutos recolectados.

- Si las nuevas generaciones dejan de ser partícipes de la piñonada y la veranada, dejan también de ser re-productores de los conocimientos que revela la interacción entre los humanos y la naturaleza, y pasan a ser receptores pasivos mediante la transmisión oral y el recuerdo de lo que vivieron sus ancestros. Es decir, el conocimiento sobre las propiedades de las plantas y otros elementos de la naturaleza, las técnicas de recolección y su procesamiento son transmitidos en el vacío, sin la práctica concreta.

Se prohíben también el ingreso de animales domésticos, por lo tanto, la cantidad de la recolección disminuye, ya que era usual subir a caballo y bajar con al menos dos sacos de piñón para el consumo en los meses siguientes. Las formas de subsistencia sufren alteraciones, afectando la riqueza culinaria de las comunidades, a la vez que el satisfactor de la subsistencia deja de estar en los faldeos del Rucapillán y es parcialmente sustituido por el mercado como proveedor de alimentos. Se genera una mayor demanda de otros bienes sustitutivos del piñón y de los frutos que ahí se recolectaban. 
También el pastoreo de los animales, que es prohibido por la CONAF, genera pobrezas en la subsistencia. Parte del interés de esta actividad es que los animales consuman frutos nutritivos y además lawen, así obtienen carne mucho más sana para su consumo. Cuando el pastoreo no es posible, la alimentación de los animales en verano es sustituida por productos concentrados disponibles en el mercado, o los que las instituciones estatales como el Instituto de Desarrollo Agropecuario (INDAP) recomienda como parte de su asistencia técnica, donde la colonialidad del saber se impone.

Además de las prácticas señaladas, existen otras de carácter cotidiano relacionadas con las vivencias personales. El tránsito de los significados colectivos a la apropiación y vivencia personal, establece vínculos particulares con el territorio. En busca de actualizar la necesidad de ocio, algunas personas transitan desde sus comunidades hacia las faldas del volcán, con el único objetivo de recrearse, recargar energía. Las necesidades de creación, ocio, libertad y entendimiento se ven limitadas por el establecimiento de las fronteras del parque. Explorar el territorio y conocerlo profundamente se torna difícil.

También es un satisfactor de la necesidad de protección. Esta parte del territorio proporciona lawen a las comunidades, es como su farmacia, en donde las plantas por sí mismas no otorgan la cura sino que vienen impregnadas de la energía del lugar. Se ubica acá una sinergia con el entendimiento en tanto se requieren los saberes para administrar la medicina, oficio que realizan las lawentuchefe ${ }^{11}$ y las machi ${ }^{12}$.

Como forma de afrontar el despojo y las presiones externas para desplazar la satisfacción de las $\mathrm{NH}$ actualizadas en el PNV, se recurre a múltiples estrategias de resistencia, mediante las prácticas cotidianas que contradicen la normativa institucional o mediante la autonomía relacionalque posibilita la negociación con otros modos de vida. También aparecen satisfactores de las NH que inhiben los propios, algunos de ellos son:

- La venta de terrenos bajo condiciones (i) legales, como mecanismo para enfrentar la pobreza material de las familias, teniendo como consecuencia la participación en un mercado inmobiliario que enajena las tierras mediante mecanismos de despojo velados,

- Lamigración de los más jóvenes en busca de oportunidades laborales, genera la asimilación de otros modos de vida que permean las dinámicas comunales al momento del retorno.

- La aceptación de que las tierras restituidasestén ubicadas fuera de territorio mapuche, provocando desintegración de las comunidades, el desarraigo y la desestructuración territorial.

- Algunas familias amortiguan su condición de vulnerabilidad complementando sus actividades productivas habituales, con otras asociadas a la actividad turística. 
Sumado a lo anterior, mediante las políticas gubernamentales impulsadas en las últimas décadas, se perpetúa hasta la actualidad la invisibilización de los conocimientos ancestrales sobre el territorio, colonialidad del saber. La CONAF se asume como garante de los saberes y con el poder de definir la vocación socioeconómica de la zona. Se posiciona como asesor y promotor del desarrollo, impone formas de participación en la gestión de la unidad natural, colocando como centro los objetivos de conservación para los cuales las comunidades aledañas asumen responsabilidad. Además, les definen las actividades económicas que pueden desarrollarse, dificultando su autodeterminación.

En síntesis, el despojo de los satisfactores trae "pobrezas" al pueblo Mapuche, la mayoría, provocadas por un largo proceso de no reconocimiento e irrespeto de las diferencias culturales, de apropiaciónterritorial violenta y sistemática, de entronización de la dependencia, de colonialidad del ser, del poder, y del saber.

\section{Desarrollo endógeno como forma de afrontar las pobrezas}

En la resistencia a las múltiples pobrezas generadas por la constitución del PNV, las comunidades van fortaleciendo sus formas de ser, estar, tener y hacer en el territorio, es decir, frente al despojo y a la construcción social de ser carenciado, los mapuche logran construir herramientas que les permiten perpetuarse como cultura viva y r-existir, en diálogo con instituciones regionales, nacionales e internacionales.

\section{Potencialidades y autodependencia}

La concepción de territorio integrado, propia de la cosmovisión mapuche, reconoce una unidad compleja. Es decir, de las actividades que se realicen en el territorio, dependerá la calidad y abundancia de todos los elementos de la naturaleza, por eso, no puede separarse lo que se haga arriba en el Rucapillán, de lo que sucede en el Lago Calafquén. Hay una conexión de todo el territorio, que refleja una conciencia ambiental y complejidad en su visión del mapu (tierra).

En su conexión con el territorio, las comunidades logran actualizar sus necesidades humanas fundamentales, de forma particular de acuerdo a su cosmovisión. El ser mapuche resulta entonces una potencialidad para la construcción de espacios donde se conviva en equilibrio con la naturaleza.

Los jóvenes de la comunidad Marifilo (parte de la comunidad Juan Chañapi) se autodefinen como jóvenes mapuche, a partir de su necesidad de identidad cultural. No basta con su relación sanguínea y la vivencia misma de algunas prácticas mapuche, sino que hay un fuerte interés que caracteriza a su generación, el interés por mantener su cultura, reapropiarse mediante el intercambio intergeneracional del conocimiento que le ha sido 
negado por sus padres, en especial el idioma, la medicina y las prácticas productivas (notas de campo, 20-6-015).

La esperanza de recuperación cultural lleva a los jóvenes a hacer uso de todo el conocimiento transmitido oralmente por sus ancestros y potenciarlo. En este intento,se potencia la relación armónica entre el ser humano y la naturaleza, mediante el aprendizaje de ceremonias y ritos donde se establece comunicación con lo no-humano.

La juventud aprende a pedir permiso, pues sabe los riesgos de entrar a un lugar que tiene dueño, sin hacer un acto ceremonial de autorización. Así, en recorrido que se realiza con ellos al PNV, llevan muday ${ }^{13}$, para entregarle a la madre naturaleza, y se hace la rogativa para evitar los riesgos de perderse o tener un accidente. Estas prácticas, transmitidas por los padres, contribuyen a la sustentabilidad del territorio en tanto se respeta la naturaleza, la reconocen como ser viviente, como un igual.

En la interrelación entre el ser humano y la naturaleza, desde la cosmovisión mapuche, se supera el concepto de conservación, ya que para estas comunidades no tiene sentido conservar bajo una condición dicotómica; por eso, se plantea cambiar de prácticas de conservación hacia el "resguardo", es decir, se hace "uso del espacio, pero de forma ancestral, sustentable, un uso espiritual” (Chocorí, comunicación personal, 23-4-2015). Esta concepción busca evitar la sobreexplotación del territorio, mediante la recuperación de prácticas ancestrales de gran vigencia en la actualidad.

La sobreexplotación se explica en las dinámicas del mercado y los hábitos de consumo de sociedades que consideran válida su reproducción, a partir del uso de recursos naturales geográficamente multisituados, expoliando a comunidades lejanas a ellos geográfica y simbólicamente, de los bienes ecológicos a los que deberían tener acceso. El acceso a los bienes ambientales y a los derechos mínimos necesarios para una existencia decente, debe permitir la actualización de las necesidades básicas fundamentales. Como lo señala Riechman la satisfacción de necesidades "en el caso de las poblaciones más pobres del planeta que viven dentro de economías de subsistencia, tiene mucho que ver con el acceso directo a bienes ambientales...” (2000, p. 226).

Frente a una racionalidad occidental donde se fracciona y monetariza la naturaleza y los modos de vida -racionalidad fundada sobre el despojo de territorios ancestrales de las comunidades mapuche- estas comunidades se resisten a morir recuperando y recreando diferentes prácticas, con una dinámica de resistencia-existencia.

Las ya mencionadas veranadas favorecían en el pasado el valor de uso, dado que ni la buena nutrición de los animales, ni la fertilización de las tierras dependían del consumo de bienes disponibles en el mercado; igual sucede con las piñonadas, donde el piñón formaba parte de los bienes que la naturaleza tenía disponibles; estas actividades generaban 
sinergias entre las necesidades humanas como lo es el conocimiento, el ocio y la identidad.

Otra práctica, menos reivindicada, pero que persiste son las "mingas", estas generan trabajo colectivo, promueven valores de cooperación y transforman el valor de cambio del trabajo hacia el valor de uso, constituyéndose un espacio para el ocio, el conocimiento y el afecto.

Las organizaciones que trabajan por la recuperación territorial, utilizan múltiples mecanismos y diferentes escalas de incidencia. A través de la enunciación de cada lugar desde su idioma, el mapuzungún, la comunidad Carlos Antimilla trabaja un proyecto de construcción de rótulos con los nombres originarios de cada lugar que sustituyan los actuales, tanto en la ciudad como en el PNV, de tal forma que el idioma sea un vehículo para recuperar su "identidad” y se facilite la transmisión y construcción de saberes (BH, comunicación personal, 23-5-2015). Es decir, recobrar la toponimia se percibe como una forma de reapropiarse del territorio, una reivindicación política desde el saber mapuche, donde cambiar un nombre como Coñaripe y devolverle su nombre originario Conarrupu -que significa senda del noble, un noble que es un líder espiritual, dominante de diferentes elementos- tiene una importancia trascendental, tanto política como cultural.

La recuperación de los territorios del Rucapillán y sus faldeos es necesaria para la sobrevivencia de las comunidades que se han relacionado ancestralmente con él. Incidir en el territorio, reapropiarse de él, resulta fundamental para hacer viable la autodeterminación, según señala Beatriz Chocorí, “...es clave en el desarrollo para nosotros como Mapuche...” (Comunicación personal, 23-4-2015).

La búsqueda de reapropiación territorial genera una serie de potencialidades relacionadas con la organización política (participación), la identidad, la libertad, la creación, fundamentales para generar "embriones de autodependencia”, tal como lo señala el DEH. La búsqueda de autodependencia posibilita la construcción de modos de vida alternativos al modelo hegemónico de desarrollo, basado en el crecimiento y la expoliación de la naturaleza.

Desde algunos miembros de las comunidades se reconoce que la población mapuche no es por si misma sustentable en términos occidentales, lo cual se atribuye a los procesos de asimilación y adaptación experimentados. A pesar de esto, reconocen como una potencialidad los saberes previos acerca de la naturaleza en el territorio que reclaman. Un adulto mayor de la comunidad señala que ellos ya conocen muchos de los conceptos de los que les vienen a hablar los funcionarios de las instituciones, tales como biodiversidad, en donde los antepasados hablaban de "Ixofij Mogen" o “diferentes formas de vida” (EH, comunicación personal, 28-6-2015).

Todas las potencialidades señaladas dan cuenta de que las comunidades aledañas al parque, tienen recursos no materiales que pueden entrar 
en juego para "resguardar” el territorio, desde su propia visión de mundo. Igualmente, son un recurso para superar las pobrezas que les generó el "alejamiento del territorio", cuando se destinó a parque nacional. El ejercicio de su autonomía y autodeterminación en lugares de uso ancestral es un derecho consignado en la legislación internacional.

En el discurso de miembros de estas comunidades cuyas luchas territoriales son también luchas por la autonomía, la palabra “desarrollo" se encuentra presente, aunque su contenido sea resignificado. Esta situación se identifica en lo manifestado por la dirigente Chocorí, cuando habla de "el desarrollo" para los mapuche.

\section{Potencialidades y articulación orgánica}

Como parte de su cosmovisión, la articulación entre el ser humano y la naturaleza es uno de los aportes fundamentales de las comunidades colindantes con los faldeos del Rucapillán, al resguardo del territorio. La visión holística del territorio contribuye a gestionarlo, considerando su complejidad. Sin embargo, hay que tomar en cuenta los procesos de empobrecimiento vividos, que obligan a construir espacios para la recuperación y reforzamiento de los saberes y prácticas que se ponen en valor.

Además de las potencialidades internas presentes en las comunidades locales, la puesta en común del despojo y luchas que han vivido otros pueblos indígenas de diferentes latitudes, influye en las demandas por la reapropiación de sus territorios. Confluyen, además, las transformaciones políticas experimentadas por Chile a partir de los años 90, y el posicionamiento a nivel internacional de los pueblos originarios de América Latina y el mundo en la búsqueda de su autodeterminación y el respeto a sus modos de vida.

Sus reivindicaciones territoriales, los torna ambientalistas, tal como lo plantea el movimiento de justicia ambiental, pues en el camino por defender su cultura, y sus modos de vida, necesariamente defienden la naturaleza a la que se encuentran vinculados (Leff, 1995). La articulación con la esfera internacional fortalece e impulsa el trabajo local.

Por otro lado, las experiencias previas de negociación con el Estado, mediante el ejercicio de la autonomía relacional, son un referente para articular acciones entre estas comunidades locales y el ámbito nacional.

El intento por definir acuerdos con la administración del parque para hacer uso de su biodiversidad, a partir de las prácticas tradicionales de recolección de piñón, es una de esas experiencias. En el año 2011-2012, se diseña, en conjunto con los administradores del parque, un "decálogo del piñonero" que pretende posibilitar el ingreso de personas mapuche a recolectar el piñón, utilizando prácticas sustentables; así establecen cuotas de extracción, reglas de ingreso al lugar y formas de compensación mediante la siembra de una parte de lo recolectado (AÑ, comunicación personal, 19-5- 
2015). Aunque este documento no se implementa por cambios administrativos, la experiencia comunitaria desarrollada en la construcción del decálogo, deja patente lo significativo de la práctica, la necesidad del territorio para recrearla y la capacidad creativa de las comunidades para recuperar conocimientos y ponerlos en valor para su uso político.

Las nuevas formas de organización, presentes en el territorio, son, también, un elemento que busca el diálogo intercultural, mediante la autonomía relacional. La “coordinadora”, organización donde participan representantes de varias comunidades, es un caso elocuente en la búsqueda de articular las necesidades comunales con los intereses del Estado y de los no mapuches que son parte de sus territorios.

Las relaciones intergeneracionales son parte de las potencialidades presentes en el territorio.Los jóvenes, en la búsqueda por "recuperar" su identidad mapuche, establecen vínculos con los pares que reafirman sus necesidades y los acerca a otras generaciones y otras comunidades vecinas. Se establecen entonces articulaciones interfamiliares, intergeneracionales e intercomunales.

Frente a los proyectos institucionales para el desarrollo turístico del PNV, algunos líderes y lideresas han planteado cogestionarlo, como una alternativaque pone en valor las potencialidades de las comunidades aledañas a esta unidad de conservación, en un intento de diálogo con el Estado. La cogestión es vista como una oportunidad de reapropiación del territorio, una forma de lograr paulatinamente la autodeterminación de espacios que les fueron despojados; una alternativa para la construcción de autodependencia de las comunidades, en tanto pueden incidir en las decisiones de su territorio, gestionar sus propias iniciativas de desarrollo a escala comunal, y por tanto atender sus necesidades humanas fundamentales, a la vez hacer un uso territorial sustentable.

\section{Conclusiones}

El desplazamiento de las comunidades mapuche ha implicado el despojo no solo material, sino también cultural y económico, ya que se pasa de modos de satisfacer las necesidades básicas fuera del mercado a la generación de prácticas cotidianas que se actualizan con la moneda.

Por su parte, en el contexto estudiado, se identifican diferentes pobrezas materiales einmaterialesque inciden sobre la calidad de vida de las personas. A diferencia de la pobreza medida por un umbral de ingreso, sus implicaciones son más profundas, pues afecta dinámicas personales y colectivas en diferentes escalas, niveles y dimensiones.

La autodependencia es un marco de análisis que permite construir puentes desde las pobrezas a las potencialidades. Esto es, R-existir en condiciones adversas como lo hacen las comunidades ancestrales que colin- 
dan al sur con el Rucapillán y sus faldeos, propicia laproducción y potenciación de capacidades, invisibilizadas en un modelo de desarrollo dominante que no considera la diversidad, homogeniza y universaliza la cultura y los modos de vida.

Existe una relación entre acceso a los bienes y servicios de la naturaleza, la incidencia de pobrezas materiales y simbólicas, y las resistencias a los procesos de despojo territorial. Como opción para superar las pobrezas generadas por la conservación de la zona estudiada, se identifica la reapropiación como un requerimiento que propende comunidades autodependientes y articuladas en diferentes niveles y escalas.

Es imperativo superar la visión tradicional de pobreza, para lograr atender la problemática de modo integral considerando el acceso a los bienes y servicios de la naturaleza. Si la pobreza se analiza como un fenómeno complejo, si se consideran las potencialidades, capacidades y saberes de los pueblos, las políticas asistenciales no son de modo alguno una solución. Es necesario abrir espacios para la construcción endógena de un “desarrollo” alternativo al modelo dominante. A lo largo de este trabajo se insiste en el uso de la palabra desarrollo, por cuanto en las mismas comunidades el planteamiento de alternativas refieren a ese término aunque le dan otro contenido, más relacionado con el buen vivir.

Una posibilidad de coadministrar el parque tiende a dinamizar la economía local y, por tanto revierte, los procesos de emigración económica experimentada por los jóvenes, preocupación que se encuentra presente en la población mapuche de avanzada edad, al considerar un peligro para su cultura la necesidad de los jóvenes por migrar ante la falta de oportunidades en sus comunidades.

Dar contenido diferente al parque, donde se establezca una nueva relación ser humano-naturaleza, liderada por las comunidades mapuche, requiere la reconstitución de los espacios de uso familiar, de recreación y transmisión de la cultura, sus prácticas, usos, historias y la revitalización de estas en espacios dinámicos de intercambio entre generaciones.

En la expresión de la lideresa Chocorí, “sin territorio no se puede hacer ejercicio de la cosmovisión”, queda patente la necesidad de dar materialidad a las ideas y al lenguaje que dice sobre cada uno de los espacios de uso ancestral, especialmente, el parque como bien común. La co-administración, como aspiración y derecho de las comunidades que lo colindan, es una posibilidad económica, política y cultural de r-existencia. Como señala Escobar, estos modelos de conservación

...implican nuevas formas de colonización del paisaje biofísico y humano, pero también pueden contribuir a la creación de nuevas posibilidades políticas para las comunidades locales. La respuesta depende, en gran medida, del grado en que las comunidades locales se apropien y utilicen los nuevos significados para lograr sus pro- 
pios objetivos, relacionándolos con otras identidades circuitos de conocimiento y proyectos políticos(Escobar,1999, p. 218).

Desde este abordaje, sería posible un DEH, con autodependencia, articulaciones orgánicas en diferentes escalas y la actualización positiva y sinérgica de las necesidades humanas fundamentales, es decir, un desarrollo que no genere pobrezas sino riquezas.

\section{Agradecimientos}

Este artículo presenta parte de los resultados de la tesis titulada: "Rexitencia de comunidades Mapuche en el Parque Nacional Villarrica. Aportes del Desarrollo a Escala Humana para la Justicia ambiental”, como requisito para optar por el Magíster en Desarrollo a Escala Humana y Economía Ecológica de la Universidad Austral de Chile. La investigación fue financiada por la Universidad de Costa Rica.Gracias al Rukapillán por el Newen. 


\section{Notas}

${ }^{1}$ La teoría del desarrollo a Escala Humana es publicada por primera vez en el año1986, tres años antes de la promulgación del Convenio 169.

${ }^{2}$ Entiéndase la autodeterminación según el artículo 3 de la Declaración de las Naciones Unidas sobre los derechos de los pueblos indígenas: "Los pueblos indígenas tienen derecho a la libre determinación. En virtud de ese derecho determinan libremente su condición política y persiguen libremente su desarrollo económico, social y cultural” (Asamblea General de las Naciones Unidas, 2007).

${ }^{3}$ En el momento que se realizó esta investigación la información oficial más actualizada la aportaba el censo del 2002, es hasta el 2017 que Chile cuenta con un nuevo Censo Nacional.

${ }^{4}$ Algunos de los proyectos con esta orientación son "Programa de Transferencia Tecnológica, Turismo de Intereses Especialesy Desarrollo con Base Local en Destino Sietelagos”, ver página oficial http://trawun.cl/ ; y el "Nodo de Turismo Comunitario", ver página oficial http://melikofelen.cl/ , ambos financiados por la CORFO, Municipalidad de Panguipulli y Bosque Modelo.

${ }^{5}$ El pastoreo refiere a una actividad ancestral realizada en los faldeos del Rucapillán, donde se llevaban los animales a consumir hierba y frutos frescos durante el verano.

${ }^{6}$ El guillatún consiste en una ceremonia donde se hace la rogativa a Gnechén para que todo el territorio esté bien, está a cargo de un lonko o líder de la comunidad reconocido como tal.

${ }^{7}$ Gnechén es una deidad de las comunidades Mapuche.

${ }^{8}$ Lawen es remedio o medicina en mapuzungún.

${ }^{9}$ Fruto de la araucaria, es parte fundamental de la dieta mapuche.

${ }^{10}$ Se refiere a las rukas o casas utilizadas para hospedar durante el período de veraneo, según personas de la comunidad el nombre original de estas rukas es sayel.

${ }^{11}$ Las lawentuchefe son personas conocedoras de las plantas medicinales.

12 Las machi, además de curar utilizando plantas, establecen una conexión con el mundo de los espíritus.

${ }^{13}$ Bebida hecha de trigo fermentado. 


\section{Bibliografía}

Asamblea General de las Naciones Unidas (2007). Declaración de las Naciones Unidas sobre los derechos de los pueblos indígenas.Recuperado de http://www.un.org/esa/socdev/unpfii/ documents/DRIPS_es.pdf

Aylwin, J. (2008). ¿De quién es el Parque Nacional Villarrica? Recuperado de www.lanacion.cl/prontus_noticias_v2/site/artic/20081206/pags/ 20081206213705.html

Carpinetti, B. (2007). Una experiencia intercultural de co-manejo entre el Estado y las Comunidades Mapuches en el Parque Nacional Lanin, Argentina. Santiago, Chile: Red Latinoamericana de Cooperación Técnica en Parques Nacionales, Otras Áreas Protegidas Flora y Fauna Silvestres.

Corporación Nacional Forestal (2006). Plan Nacional de Manejo Parque Nacional Villarrica.Recuperado de http://www.conaf.cl/wp-content/ files_mf/1382466395PNVillarica.pdf

(2013). Plan de Manejo Parque Nacional Villarrica. Temuco, Chile.

Correa, M. y Mella, E. (2010). Las razones del illkun/enojo. Memoria, despojo y criminalización en el territorio mapuche de Malleco. Santiago, Chile: LOM Ediciones.

Duran, C. (2009). Gobernanza en los Parques Nacionales Naturales colombianos: reflexiones a partir del caso de la comunidad Orika y su participación en la conservación del Parque Nacional Natural Corales del Rosario y San Bernardo. Revista de Estudios Sociales, (32),60-73

Elizalde, A (2003). Desde el "Desarrollo Sustentable” hacia Sociedades Sustentables. POLIS, Revista Latinoamericana (4), 2-18. Recuperado de http://polis.revues.org/7154

Escobar, A.(1999). El final del salvaje. Naturaleza, cultura y política en la antropología contemporánea.Recuperado de https:// antroporecursos.files.wordpress.com/2009/03/escobar-a-1999-el-final-del-salvaje.pdf

FAO. (2008). Pueblos indígenas y áreas protegidas en América Latina. Recuperado en http://www.fao.org/3/a-az734s.pdf

Gobierno de Chile. (2012). Estrategia Nacional de Turismo 2012-2020. Chile. Recuperado de http://portal.mma.gob.cl/wp-content/uploads/ 2014/10/1_Estrategia-Nacional-deTurismo-2012-2020.pdf 
(2013). Parque Nacional Villarrica. Plan Maestro 2013. Desarrollo Sustentable en Áreas Silvestres Protegidas. Chile.

Guerrero, P. (2010). Corazonar, una antropología comprometida con la vida. Miradas otras desde Abya-Yala para la Descolonización del Poder, del Saber y del Ser. Quito, Ecuador: Abya-Yala.

Instituto Nacional de Estadística. (2008). División Político Administrativa y censal 2007. Santiago, Chile.

Leff, E. (1995). ¿¿De quién es la naturaleza? Sobre la reapropiación social de los recursos naturales. Gaceta Ecológica, (37), 28-35.

(2000). Espacio, lugar y tiempo: la reapropiación social de la naturaleza y la construcción local de la racionalidad ambiental. Desenvolvimento e Meio Ambiente, (1), 57-69.

(2014). La apuesta por la vida. Imaginación sociológica e imaginarios sociales en los territorios ambientales del sur. México: Siglo XXI Editores.

McCarthy, R. y Martínez, C. (2006). Dos décadas de gestión comunitaria en Centroamérica: el camino recorrido, su estado y desafíos. San José, Costa Rica: UICN. Oficina Regional para Mesoamérica. Recuperado de https://portals.iucn.org/library/efiles/documents/2006013.pdf

Martínez-Alier, J. (2014). El ecologismo de los pobres. Conflictos ambientales y lenguajes de valoración.Santiago, Chile: Editorial Quilmantú.

Max-Neef,M, Elizalde,A, Hopenhayn, M. (1998). Desarrollo a Escala Humana: Conceptos, aplicaciones y algunas reflexiones. Barcelona, España: Biblioteca CF+S.

Millalén, J. (2006). La sociedad mapuche prehispánica: Kimü, arqueología y etnohistoria. En P. Marimán, S. Caniuqueo, J. Millalén, \& R. Levil, i i...Escucha, winka...!!. Santiago, Chile: LOM Ediciones.

Municipalidad de Panguipulli. (2006). Plan de ordenamiento territorial. Zona de Interés Turístico. Comuna de Panguipulli - Destino Siete Lagos. Panguipulli. Recuperado de http://www.sietelagos.cl/files/ ZOIT\%20SIETELAGOS.pdf

(2014). Actualización Plan de Desarrollo Comunal de Panguipulli 2013 - 2017. Chile.

Riechman, J. (2000). Un apartheid planetario. Ecología, globalización y desigualdad socioeconómica. En:Un mundo vullnerable. Ensayos 
sobre ecología, ética y tecnociencia. Madrid, España: Los libros de la catarata.

Trentini, F. (2011). Entre al conservación y la legitimidad: el caso de la comunidad Maliqueo y el Parque Nacional Nahuel Huapi. Kula. Antropólogos del Atlántico Sur(4), 61- 75. Recuperado de http:// www.revistakula.com.ar/wp-content/uploads/2014/02/KULA-4-5TRENTINI.pdf

(2012). Ecología política y conservación: el caso del “Co-manejo del Parque Nacional Nahuel Huapi y el Pueblo Mapuche. Revista Pilquén, 14 (15). Recuperado de http://www.scielo.org.ar/ scielo.php?script=sci_arttext\&pid=S1851-31232012000200008

Trentini, F. y Tyelman, C. (2009). Pueblos indígenas y políticas esatales: dos experiencias de comanejo en Argentina y Canadá. Recuperado de https://www.academia.edu/784644/Pueblos_ind\%C3\%ADgenas _y_pol\%C3\%ADticas_estatales_dos_experiencias_de_comanejo_en_Argentina_y_Canad\%C3\%A1

Ulloa A (2011). Políticas Globales del Cambio Climático: Nuevas geopolíticas del conocimiento y sus efectos en territorios indígenas. Construcciones culturales sobre el clima. En A. Ulloa (Ed.), Perspectivas culturales del clima. Bogotá, Colombia. 